\title{
Technology of physical and coordination-technical improvement of firefighters and rescuers in training activities
}

\author{
Vasilij Shalaginov $^{1,3}$, Gennady Germanov ${ }^{1}$, Elena Grigorieva ${ }^{4}$, Alexey Korolkov ${ }^{5,6}$, Ekaterina Kochetkova $^{2}$ \\ ${ }^{1}$ Russian State University of Physical Culture, Sports, Youth and Tourism, 105122, Moscow, Russia \\ ${ }^{2}$ Moscow City Pedagogical University, 129226, Moscow, Russia \\ ${ }^{3}$ Academy of the State Fire Service of the Ministry of Emergency Situations of Russia, 129366, Moscow, Russia \\ ${ }^{4}$ State Pedagogical University Kozma Minin, 603005, Nizhny Novgorod, Russia \\ ${ }^{5}$ Moscow State Regional University, 141014, Moscow region, Mytishchi, Russia \\ ${ }^{6}$ Russian State Agrarian University - Moscow Agricultural Academy Named After Timiryazev K.A., 127550, Moscow, Russia
}

\begin{abstract}
The study defines pedagogical conditions that contribute to the growth of sports skills of men 19-23 years old, competing in fire and rescue sports. The conditions provide knowledge of the competitive activity laws implementation. The procedural and effective methods that solve the problems of developing physical and improving coordination and technical training of fire and rescue workers, introduce a differentiated approach to training athletes, taking into account the revealed competitive typology and predisposition to successful performance in certain applied disciplines of the sport. The model characteristics of athletes aged 19-23 years competitive activity are determined; individual and group typological features of sports performance in competitions are revealed and a differentiated approach to physical training of firefighters and rescuers is justified. The technology of combined physical and coordination-technical improvement of athletes aged 19-23 years in fire and rescue sports is developed based on the algorithm of training actions sequential change. The methodology of fire-rescue professional development is proved. There the leading party application process became sports and training activities with the use of firerescue sports. The method of training men-juniors 19-20 years old and young athletes 21-23 years old to participate in competitions in fire-rescue sports is developed. We used pedagogical experiment, pedagogical testing; instrumental methods; methods of mathematical statistics.
\end{abstract}

\section{Introduction}

There is a lack of scientific and methodological foundations of professional-applied training of fire-rescue, where training activities are given additional and related role, but not dominant in professional improvement fire-rescue. There is a contradiction between the goal-oriented aspirations of athletes to achieve high sports results in professional competitions and the systems of existing knowledge about the training of firefighters and rescuers. The private-subject methodological knowledge about sports training prevails, but they should be replaced by met subject modern knowledge about the training of athletes $[1,2,4,5,9]$. Outdated guidelines on sports training of firefighters and rescuers require new technological solutions, a different understanding of the training laws in certain disciplines of applied sports, search and approval of precise specialized techniques and technologies of physical and coordinationtechnical improvement for successfully overcoming the "100-meter obstacle course (100 OC)" and climbing the " assault ladder (AL)".

The study identified model characteristics of competitive activity, a temporal structure of action in the disciplines of fire and rescue sport, the safety factors of sports performance. Thus, the average percentage of technical performance reliability by Russian male athletes in domestic competitions in 2016 was $51.8 \%$ (100 OC) and $66.8 \%$ (ST), in 2019 the indicators were $51.4 \%$ (100OC) and $65.8 \%$ (ST). The overcoming time to the second half of the distance on the 100meter obstacle course for athletes in competitions determines the final result, the dependence is confirmed by a statistically strong correlation $(\mathrm{r}=0.761 \div 0.980$, taking into account age). The most technically difficult in the second half of the race is the receiving dock fire hose lines to a fire fork, there is a strong correlation between the time it is done with the final result ( $\mathrm{r}=0,744 \div 0,947$, accounting the age). The final result in overcoming the 100 -meter obstacle course does not have a statistically significant relationship with the overall result of climbing the assault ladder ( $\mathrm{r}=0.495)$. Thus, the 100-meter obstacle course and climbing the assault ladder are separate sports disciplines. Their specialization is carried out taking into account the differences in successful performance at competitive distances and the typology of athletes competitive actions $[3,7,8,10]$. 


\section{Materials and methods}

We analyzed the sports results of the strongest athletes of the country and the world, shown at all-Russian and major international competitions in the period 2015-2019. Electronic timekeeping was used - the Strizh-M system, which has a certified conclusion; parallel video recording was carried out with a high-speed camera " NAC Memrecam GX-8E (Japan)". The pedagogical experiment involved 24 athletes aged 19-23 years - the experimental group (EG) included 14 people, the control group (CG) consisted of 10 people. Both groups in the initial state were the same in their sports training: $60-70 \%$ of their members were candidates for master of sports (CMS), $30 \%-40 \%$ - masters of sports (MS). According to the level of physical fitness, there were no significant differences in the indicators that characterize the initial level of speed, speed-strength, coordination abilities and endurance $(\mathrm{P}>0.05)$.

\section{Results and discussion}

The first stage of the research was focused on a particular problem: determine the rational relationship between running speed in the "approach" to the bifurcation in terms of slowing down movements relative to the running speed in terms of "dispersal" after joining sleeve lines to the competitive exercise "the 100-meter obstacle course". To establish valid parameters of the running speed, the intervals of running time on a ten-meter segment were recorded when " approaching "the branch and" leaving " it after performing a technical action. The average speed of deceleration when approaching the fork in successful attempts was $4.57 \pm 0.52 \mathrm{~m} / \mathrm{s}$ for young athletes, $5.12 \pm 0.55 \mathrm{~m} / \mathrm{s}$ for qualified athletes, and $4.00 \pm 0.47 \mathrm{~m} / \mathrm{s}$ and $4.32 \pm 0.51 \mathrm{~m} / \mathrm{s}$ for unsuccessful ones. The athletes slowed down less when performed correctly and the delay time at the fork was shorter than in the case of mistakes and incorrect technical actions. The values of the correlation coefficients of running speed in successful attempts, in which the sleeve line is successfully connected to the branch, are invariant to the skill and gender of athletes and are in the range of 0.75-0.78 usl. /unit. At the same time the average running speed of adult athletes was higher than the corresponding speed of young athletes by $12 \%$.

Individual and group typological features of sports performance in firefighters and rescuers competitions were determined. The predisposition to successful performance at one of the competitive distances was diagnosed. So, as a result of clustering, groups of "remoters" (EG1) and "storm troopers" (EG2) were identified. The reliability and stability of athletes' successful performance at one of the competitive distances is associated with the subject specialization in one of them [6]. The distribution of applied athletes into typological groups, taking into account the identified strengths and weaknesses, made it possible to introduce a differentiated approach to the organization of firefighters and rescuers motor activity and to develop a method for forming the rhythmic structure of running in competitive disciplines of FRS [6].

It is necessary to provide preliminary physical fitness to form the rhythmic structure of running in competitive disciplines of fire and rescue sports. At the second stage of the study, a methodological algorithm was proposed for coordination, technical and physical improvement of male juniors 19-20 years old and young athletes 21-23 years old in fire and rescue sports based on a sequential shift of training actions. At the general preparatory stage of the macrocycle, when complex solving of motor tasks in cycles-blocks of training actions, the ratio of the conditioned training motor tasks was expressed as a proportion of $80 \%$ in relation to $20 \%$ of the MT of coordination and technical training. At the special preparatory stage of training in the experimental group, the ratio of conditioned training motor tasks was expressed as a proportion of $50 \%$ in relation to $50 \%$. At the pre-competition stage and in preparation for participation in the main starts of the season, the ratio of conditioned training motor tasks was expressed as a proportion of $20 \%$ in relation to $80 \%$. This construction of training sections contributed to the initial readiness for the rhythmic structure formation of running. In the control group used a game oriented exercises recommended in the manual on physical training state fire service of EMERCOM (2011) as optimal for the development and expression of specialists' physical and mental qualities, rescue units of EMERCOM of Russia. Sports exercises in the game of basketball, volleyball, football should be a priority in improving the physical fitness of rescuers. They develop the ability to quickly orientate, coordinate behavior in extreme conditions, and contribute to improving functional fitness.

The results of stage-by-stage pedagogical testing at the end of the first series studies showed that by the end of the preparatory period, the athletes of the experimental group (EG) had a clear advantage in terms of physical fitness over the athletes of the control group (CG). In the conditions of combined training with the accentuated development of speed-strength and speed abilities, there was a change in indicators that characterize various aspects of athletes ' fitness. The athletes of the experimental group (EG) in comparison with the control group (CG) had significantly higher average group values in running, jumping, and strength tests. The growth rate of results in control tests was also higher.

Table 1. Indicators of athletes' conditioned (physical) fitness of the experimental and control groups at the end of the preparatory period / stage 1 of the experiment.

\begin{tabular}{|c|c|c|c|c|}
\hline \multirow{2}{*}{$\begin{array}{l}\text { Control tasks } \\
\text { (Tests) }\end{array}$} & $\mathrm{EG}(n=14)$ & $\mathrm{CG}(n=10)$ & \multirow{2}{*}{ Uэмп / a } & \multirow{2}{*}{$P$} \\
\hline & $\bar{X} \pm \sigma$ & $\overline{\bar{Y}} \pm \sigma$ & & \\
\hline $\begin{array}{l}\text { 1. Running } 20 \mathrm{~m} \text { from head start, } \\
\mathrm{s}\end{array}$ & $1,94 \pm 0,05$ & $1,99 \pm 0,05$ & $35 a=95,6$ & $<0,05$ \\
\hline
\end{tabular}




\begin{tabular}{|c|c|c|c|c|}
\hline $\begin{array}{ll}\text { 2. Running } 100 \mathrm{~m} \text { from low start, } \\
\mathrm{s}\end{array}$ & $11,25 \pm 0,23$ & $11,63 \pm 0,21$ & $17,5 \quad a=99,6$ & $<0,01$ \\
\hline $\begin{array}{l}\text { 3. The long jump from the place, } \\
\mathrm{cm}\end{array}$ & $291 \pm 12$ & $275 \pm 11$ & $21,5 \mathrm{a}=99,2$ & $<0,01$ \\
\hline 4. $\quad$ Triple jump from a place, $\mathrm{cm}$ & $888 \pm 28$ & $840 \pm 26$ & $16,5 \quad a=99,8$ & $<0,01$ \\
\hline 5. 10 -fold jump from a place, $\mathrm{m}$ & $29,70 \pm 0,74$ & $28,11 \pm 0,85$ & $15 \mathrm{a}=99,9$ & $<0,001$ \\
\hline 6. $\quad$ Bench press, $\mathrm{kg}$ & $66,1 \pm 6,8$ & $60,7 \pm 7,2$ & $40 \quad a=95,2$ & $<0,05$ \\
\hline 7. Tugging to the chest, $\mathrm{kg}$ & $87,0 \pm 8,4$ & $78,0 \pm 7,1$ & $29 a=98,4$ & $<0,05$ \\
\hline 8. Squat with a barbell, $\mathrm{kg}$ & $120 \pm 8,5$ & $109 \pm 7,7$ & $22 \mathrm{a}=99,6$ & $<0,01$ \\
\hline 9. Shuttle run on $3 \times 10 \mathrm{~m}, \mathrm{~s}$ & $7,22 \pm 0,26$ & $7,30 \pm 0,19$ & $88,5 \quad a=62,7$ & $>0,05$ \\
\hline 10. Running $300 \mathrm{~m}, \mathrm{~s}$ & $38,7 \pm 1,1$ & $38,7 \pm 1,0$ & $76 a=70,0$ & $>0,05$ \\
\hline
\end{tabular}

Symbols: $\mathrm{X}$ - average values of athletes in the experimental group, $\mathrm{Y}$-average values of athletes in the control group, $\sigma$-standard deviation; U-Mann-Whitney test, P-significance level; $a=95 \%$, 99\% - confidence interval. Note. Sample arithmetic averages of unrelated groups are different if at $\mathrm{n} 1=14$ and $\mathrm{n} 2=10$, the significance level of differences is $\mathrm{a}=95 \%, \mathrm{UC}=41 \geq \mathrm{Uemp}, \mathrm{a}=99 \% \mathrm{UC}=$ $30 \geq$ Uemp.

Based on the initial physical fitness, the tasks of coordination improvement were solved. A method of forming the rhythmic structure of running in competitive disciplines of fire and rescue sports was developed. At the general preparatory stage, it was recommended to use motor tasks to increase the pace of movement, master the techniques of connecting a fire line to branching, and develop and improve special motor skills. At the special preparatory stage, motor tasks were solved with the distinction of time boundaries of actions and exercises. At the beginning they were differentiated in tasks with contrasting settings, and later the accuracy of orientation in time increased due to an increase in the number of tasks with increasingly close overlapping values. At the pre-competition stage and in the moments of preparation for the main starts of the season, the exact differentiation of the time parameters of running on certain segments when overcoming the 100-meter obstacle course and climbing the assault ladder was provided. Coordination training influence psychophysical functions, including proprioceptive and sensory components of neuropsychic regulation of actions, forming a "sense of time", "sense of space and distance", "sense of power tension and power of muscle effort".

Coordination readiness of fire-rescuers EG and CG was determined by a number of pedagogical and psychophysical tests, such as" balance in the Flamingo test"," walking test Fukuda "and" Yarotsky " test. These tests allow to assess the consistency of movements, the state of psychophysical reactions, the ability to differentiate movements. At the end of the pedagogical experiment, athletes of EG1 and EG2 have significantly higher average group values in tests that characterize coordination readiness in comparison with CG (figure 1). A significant increase in coordination abilities occurred in the first experimental group (EG1): in the Flamingo test, the number of falls decreased by $52.6 \%$, in the Fukuda walking test, the deviation from the starting point decreased by $26.8 \%$, in the Yarotsky test, the stability of the vestibular analyzer increased and the time to maintain the control pose in balance increased by $27.1 \%$. A significant increase in the second experimental group ЭГ2 occurred in the tests, characterizing the indicators of coordination abilities: in gymnastics test bench, an increase of 35.6\%; this dynamic reflects the effect from the previous coordinating technical training, organized in the second phase of the pedagogical experiment. There the rise of a hook ladder into the window on the 4 floor of a training tower is very important, coordinating body turns around the axis assault ladders. In other coordination tests, the dynamics of the results were: in the Flamingo test, the number of falls decreased by $28.0 \%$, in the Fukuda walking test, the deviation from the starting point decreased by $17.9 \%$, and in the Yarotsky test, the stability of the vestibular analyzer and the measured time spent in the control sample to maintain balance increased by $20.1 \%$.

1

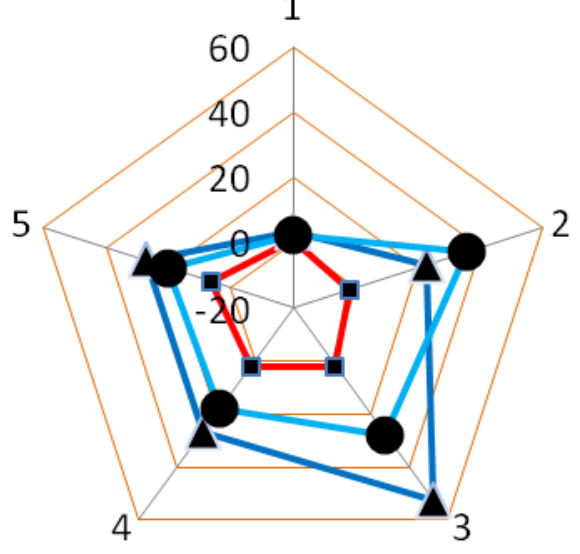


Fig. 1. Growth rates of indicators in pedagogical tests, characteristics of the dynamics of coordination abilities in experimental athletes (EG1 ; EG2) and control groups (CG) at the end of the pedagogical experiment, \%

Symbols: 1-Double long jump from a place sideways; 2-Gymnastic bench, number of $360^{\circ}$ turns in 20 seconds; 3-Flamingo Test, number of falls in; 4-Walking Fukuda test, deviation from the starting point; 5 - Yarotsky Test.

The method allows to increase the accuracy of connecting the sleeve line to the branch line up to $70 \%$. This increases not only the frequency of correct connections, but also the competitive result of passing the distance (table 2). The increase in results for athletes in the experimental group was about $4.1 \%$.

Table 2. Indicators of athletes' competitive performance in experimental (EG1) and control group (CG) in overcoming the 100-meter obstacle course during the main competition/stage 2 of the experiment $(-\mathrm{M} \pm \sigma)$.

\begin{tabular}{|l|c|c|}
\hline \multicolumn{1}{|c|}{ Indicators } & $\begin{array}{c}\text { Athlets EG } \\
(n=7)\end{array}$ & \multicolumn{1}{c|}{$\begin{array}{c}\text { Athlets CG } \\
(n=10)\end{array}$} \\
\hline Average result, s & $15,84 \pm 0,35$ & $16,40 \pm 0,49$ \\
\hline$U$-criteria, P-reliability & \multicolumn{2}{|c|}{ Uэмп=13 $\quad \mathrm{a}=98,2 \quad \mathrm{P}<0,05$} \\
\hline Speed correlation coefficient (deceleration / acceleration) & $0,78 \pm 0,05$ & $0,72 \pm 0,04$ \\
\hline The ratio of successful attempts to all attempts, $\%$ & 70 & 54 \\
\hline Sports category & MC $100 \%$ & MC 50\% \\
\hline
\end{tabular}

In competitions of applied EG athletes on the assault ladder, technical actions were error-free and reliable. High coordination readiness and appropriate rhythmic structure of running in EG2 athletes in overcoming the assault ladder were higher and significantly different from the values of CG athletes (table 3). The growth rate of sports results in EG2 athletes was $4.2 \%$, in $\mathrm{KG}$ athletes - only $0.8 \%$.

Table 3. Indicators of athletes competitive performance of the experimental (EG2) and control group (CG) in climbing the assault stairs to the window of the 4th floor training tower during the main competition / stage 2 of the experiment ( $\square \mathrm{M} \pm \sigma$ )

\begin{tabular}{|l|c|c|}
\hline \multicolumn{1}{|c|}{ Indicators } & $\begin{array}{c}\text { Athlets EG } \\
(\mathrm{n}=7)\end{array}$ & $\begin{array}{c}\text { Athlets CG } \\
(\mathrm{n}=10)\end{array}$ \\
\hline Average result, s & $13,75 \pm 0,33$ & $14,23 \pm 0,33$ \\
\hline$U$-criteria, P-reliability & \multicolumn{2}{|c|}{$U_{9 \text { эп }=9,5 \quad \mathrm{a}=99,2 \quad \mathrm{P}<0,01}$} \\
\hline The ratio of successful attempts to all attempts, $\%$ & 77 & 58 \\
\hline Sports category & MC 85\% & \multirow{2}{*}{ MC 30\% } \\
\hline
\end{tabular}

\section{Conclusions}

Paired problem solving and the formation of the running rhythmic structure is effective in terms of the proportional relationship of motor tasks. The tasks involve development of conditional and coordination abilities, their proportion in realization the main parties of athletes preparedness at various stages of the macrocycle.

The differentiated approach to improving the sports and technical skills of juniors 19-20 years old and young athletes 21-23 years old, contributes to the formation of a rhythmic structure of running in competitive disciplines of fire and rescue sports.

Mastering the rhythmic structure of running in competitive disciplines of fire and rescue sports leads to an increase in results and a successful performance in competitions in fire and rescue sports. It also leads to anaccurate performance of technical actions by athletes - joining the fire hose line with the fire branch in overcoming the " 100 meter obstacle course "and quickly climbing the "assault ladder to the window of the 4th floor training tower".

\section{References}

1. V.M. Velichko, Fire-applied sports: manual (Polytope Publ., Moscow, 2014)

2. A.S. Kuznetsov, Z.M. Kuznetsova, Russian Journal of Physical Education and Sport, 14(4), 5-7 (2019). DOI: 10.14526/20704798-2019-14-4-5-7

3. A.N. Korolkov, G.N. Germanov, V.D. Shalaginov, I.V. Mashoshina, Rescue and firefighting sport: theory of the training and technologies: monograph (Iva Pub., Voronezh, 2019)

4. G.N. Germanov, A.N. Korolkov, V.D. Shalaginov, I.V. Mashoshina, Rescue and firefighting sport, manual (Yurayt publishing house, Moscow, 2020) 
5. V.D. Shalaginov, G.N. Germanov, A.N. Korolkov, I.V. Mashoshina, Scientific notes of University named after P.F. Lesgaft, 179(1), 330-335 (2020)

6. I.V. Strelnikova, Ways of solving efficiency of classes in physical culture and sports (Kirov, 49-51, 2007)

7. S.K. Shoygu, M.I. Faleev, G.N. Kirillov et al, Textbook by the rescuer (Moscow, 2002)

8. D.N. Grigorenko, K.K. Bondarenko, S.V. Shilko, Russian Journal of Biomechanics, 15-3(53), 51-59 (2011)

9. M. Krasnokutskyi, Slobozhanskyi herald of science and sport, 2(46), 78-84 (2015)

10. B. Škodová, Metodika disciplíny požárni útok (Mladá fronta. Praha, 2014) 